\title{
Development of Thermal Conductivity Measurement Test Rig for Engineering Material
}

\author{
Dinesh Kumar ${ }^{1}$, Prakash Chandra ${ }^{2}$ \\ ${ }^{1,2}$ (Department of Mechanical Engineering, National Institute of Technology Patna, India)
}

\begin{abstract}
This paper describe the development of a hot rod method by using water as a coolant medium which measure the heat loss through the rod for the steady state measurement of thermal conductivity of small samples. The heat flow through the test sample was essentially one dimensional and heat loss through engineering material is made to use heated guard to block the flow of heat from the hot rod to the surroundings. Since large correction factors must be applied to account for guard imperfection and not maintained ideal condition. So that it may be preferable to simply measure and correct for the heat that flows from the heater disc to directions other than into the sample. Experimental measurements taken in a prototype apparatus combined with extensive computational modeling of the heat transfer in the apparatus show that sufficiently accurate measurements can be obtained to allow determination of thermal conductivity of engineering material. Suggestions are made for further improvements in the method based on results from regression analysis of the generated data.
\end{abstract}

Keywords: Thermal Conductivity, Sensor, Thermal Insulation, Microcontroller, Steady State Technique.

\section{Introduction}

Thermal conductivity is the physical property of the material denoting the ease with a particular substance can accomplish the transmission of thermal energy by molecular motion. Thermal conductivity of a material depends on the chemical composition of the substance or substances of which it is composed, the phase (i.e. gas, liquid or solid) in which it exists, its crystalline structure of a solid, the temperature and pressure to which it is subjected. It also depends on whether the material is homogeneous or not. In all solids, energy may be transferred by means of elastic vibrations of the lattice moving through the crystal in the form of waves. In some solids, notably metals, free electrons moving through the lattice also carry energy in a manner similar to thermal conduction by a true gas phase. At ordinary temperature all solids store thermal energy as vibratory motion of their atoms and potential energy in the bonding between atoms. Therefore the thermal conductivity is related to the heat capacity.Because the selection of measuring method for thermal conductivity had significant role in this work, a brief review of thermal conductivity measurement methods was warranted and had to be included in this thesis. Two general classifications of thermal conductivity measurement methods were reported in literature: (i) steady-state and (ii) transient state methods. In either case the measurement may be absolute or comparative. The difference in thermal conductivity values for absolute or comparative cases is because comparative methods require the property of another material in the calculation of a test sample thermal conductivity, typically a distinct disadvantage. Jensen et al. included a more complete overview of common methods.

Jensen et al. [2] worked on validation of a thermal conductivity measurement system for fuel compacts. A high temperature guarded-comparative-longitudinal heat flow measurement system has been built to measure the thermal conductivity of a composite nuclear fuel compact. It was a steady-state measurement device designed to operate over a temperature range of $300 \mathrm{~K}$ to $1200 \mathrm{~K}$. No existing apparatus is currently available for obtaining the thermal conductivity of the composite fuel in a non-destructive manner due to the compact's unique geometry and composite nature. The current system design has been adapted from ASTM E 1225. As a way to simplify the design and operation of the system, it uses a unique radioactive heat sink to conduct heat away from the sample column. A finite element analysis was performed on the measurement system to analyse the associated error for various operating conditions. Optimal operational conditions have been discovered through this analysis and results are presented. Several materials have been measured by the system and results are presented for stainless steel 304 , Inconel 625 , and $99.95 \%$ pure iron covering a range of thermal conductivities of $10 \mathrm{~W} / \mathrm{mk}$ to $70 \mathrm{~W} / \mathrm{mk}$.

Alam et al. [7] worked on thermal property of engineering material and analysis of insulating materials. In this study [7], thermal conductivity of insulating materials were determined and compared with the values reported in literature. Lee's and Charlton's apparatus was used to measure the property of insulating materials by steady state technique. This apparatus provide more precise result for insulators and it may be utilized for the further thermal related analysis. For this work an experimental set up was prepared to determine and analyse the thermal conductivity of insulating materials. The thermal conductivities obtained by this apparatus for the 
material borosilicate glass, styrene butadiene rubber, and polyolefin foam faced aluminium foil were $0.797 \mathrm{~W} /$ $m K, 0.3023 \mathrm{~W} / \mathrm{mK}$ and $0.057 \mathrm{~W} / \mathrm{mK}$ respectively. The experimental results were found 9-30\% deviation from the values reported in literature.

Hooper et al. [10] worked on error in heat flow in axial direction, the ratio of the probe length to outside diameter, $L / d$, was an important value to indicate possible error from axial heat flow within the probe. The line heat source theory assumes one-dimensional radial heat flow, and small $L / d$ ratios may indicate more induced error from axial flow. Anterior researchers noted that investigators have recommended minimum values for the heater $L / d$ ratios which range from 31 to 100 . Hooper and Lepper [10] also recommend $L / d$ ratio of at least 100 to minimize error from axial heat flow.

Presley et al. [11] recommend using a highly conductive sheath to improve gap conductance, such as, stainless steel or aluminium and its alloys. Good thermal contact between the probe and the sample material increases accuracy. Poor contact will delay the material response time, and thus, make slope estimates difficult. To enhance accuracy, thermal grease was recommended by ASTM Standard to minimize uncertainties from poor sample-to-probe contact.

Wang et al. [12] worked on photoacoustic measurement of thermal conductivity measurement of thin films and bulks materials. The photoacoustic (PA) technique was one of many techniques for measuring thermal conductivity of thin films. Compared with other techniques for thermal conductivity measurement, the photoacoustic method was relatively simple, yet is able to provide accurate thermal conductivity data for many types of thin films and bulk materials. In this work [12], the PA measurement in a high frequency range was made possible by a newly developed PA apparatus, which extends the limit of the PA technique. Thermal conductivities of $\mathrm{SiO}_{2}$ with thicknesses from 0.05 to $0.5 \mathrm{~mm}$ on $\mathrm{Si}$ wafer, e-beam evaporated thin nickel film on $\mathrm{Si}$ wafer, and thermal barrier coatings were obtained. In addition to the commonly used phase shift fitting, which was only appropriate for thermally-thin films, an amplitude fitting method is developed and employed for measuring both thin films and bulk materials with smooth or rough surfaces.

Stojanovic et al. [13] analysed for thin-fin the thermal conductivity measurement using microelectrothermal test structure. A new method for measuring thermal conductivities of films with Nano scale thickness has been proposed. The method combines a microelectrothermal test structure with a finite-element based data analysis procedure. The test device consists of two serpentine nickel structures, which serve as resistive heaters and resistance temperature detectors, on top of the sample. The sample is supported by a silicon nitride membrane. Analytical solution of the heat flow is infeasible, making interpretation of the data difficult. To address this, we use a finite-element model of the test structure, and apply nonlinear least-squares estimation to extract the desired material parameter values.

Rayeshi et al. [14] presented a paper on analysis of one dimensional hyperbolic heat conduction in a functionally graded thin plate. In this paper presents the analytical solution of one-dimensional non-Fourier heat conduction problem for a finite plate made of functionally graded material. To investigate the influence of material properties variation, exponential space-dependent functions of thermal conductivity and specific heat capacity are considered. The problem was solved analytically in the Laplace domain, and the final results in the time domain are obtained using numerical inversion of the Laplace transform (LT). The trial solution method with collocation optimizing criterion has been applied to solve the hyperbolic heat conduction equation based on polynomial shape function approximation. Due to the reflection and interaction of the thermal waves, the temperature peak happens on the insulated wall of the FGM plate, so the major aim of this paper is to find the amount of temperature peak and the time at which it happens. It has been shown that the dimensionless temperature peak and its happening time increase along with an increase in the dimensionless relaxation time. The results are validated by comparison with the results from an exact available solution solved at special case which shows a close agreement.

Miyazaki et al. [15] presented a paper on, "Heat Conduction of a Porous Material". In this paper, numerical and experimental works were presented for the thermal conductivity reduction by using a porous material. Recently thermal conductivity reduction has been one of the key technologies to enhance the figure of merit (ZT) of a thermoelectric material. Numerical calculations of heat conduction in porous materials were carried out, such as phonon Boltzmann transport (BTE) and molecular dynamics (MD) simulations, in order to investigate the mechanism of the thermal conductivity reduction of a porous material. In the BTE, the periodic boundary conditions with constant heat flux have been applied to calculate the effective thermal conductivity of porous materials. Nano particles were prepared by beads milling method. The thermal conductivity is one-fifth of that of a bulk material as well as keeping the same Seebeck coefficient as the bulk value. 


\subsection{Experimental Setup}

\section{Experimental Setup \&Procedure}

The experimental set up consists of the metal bar, one end of which is heated by an electric heater while the other end of the bar projects inside the cooling water. The middle portion of the bar is surrounded by a cylindrical shell filled with the plaster of peris. The temperature of the bar is measured at two different positions, while the radial temperature distribution is measured by separate thermocouples at two different sections in the insulating shell. The method of determining thermal conductivity by axial heat flow through a long cylindrical sample is used. The schematic diagram of the apparatus for measuring thermal conductivity is shown in Figure1.The material rod consists of concentrically mounted sample, thermal shield, vacuum container, plaster of peris fill around the cylindrical pipe. The sample rod is clamped to the heat sink at the top; the sample heater is attached to the bottom of this rod. The temperature distribution along the sample is measured by means of two thermocouples attached to thermocouple holders positioned along the rod. Heat losses by gas convection and conduction are made negligible by evacuating the region surrounding the sample.

Losses by radiation and conduction along the lead wires are reduced by enclosing the sample rod maintained at approximately fixed temperature within a symmetric cylindrical thermal shield. Axial gradient as the sample, measurements of the temperature, thermal gradient, and power input to the sample, combined with data on the cross-sectional area permit a calculation of the thermal conductivity of the sample based upon Fourier's equation for steady state linear heat flow. The heat sink is maintained at a constant lowtemperature by a refrigerant, usually water. The water tank is surrounded by thermocol which reduces the heat from water to the surrounding atmosphere.

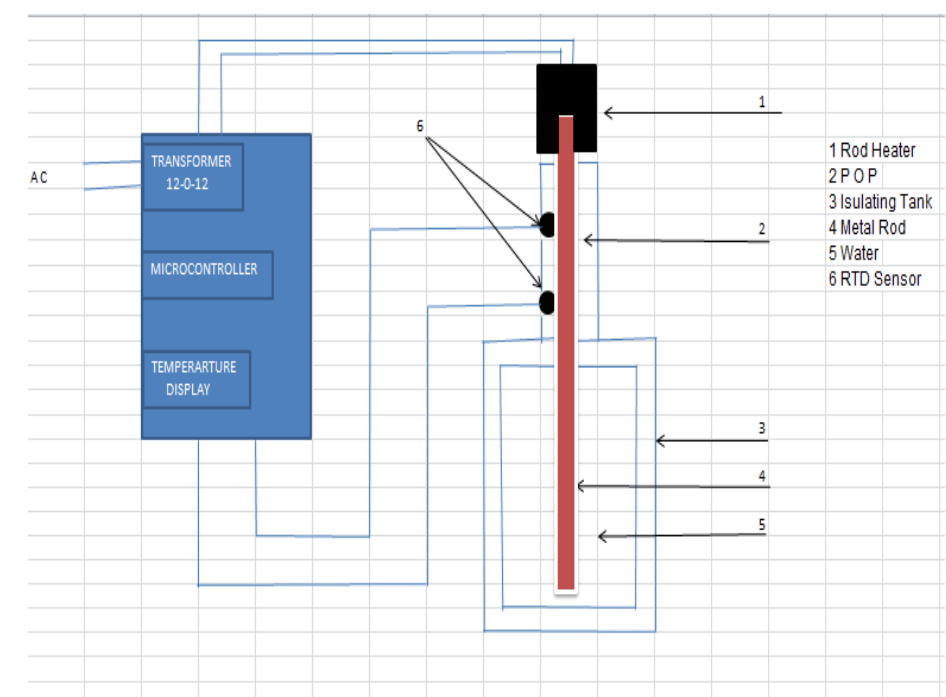

Figure 1: Schematic Thermal Conductivity Measurement Apparatus

\subsection{Working Procedure}

The working procedures of the experiment for thermal conductivity measurement of test sample are summarized as follows.

1. The length of test section and diameter of the sample were measured and the values have been noted down.

2. The main switch of power supply has been put on.

3. Before turning heating or cooling, all the temperature readings (at all points 1-2) has been checked. If the apparatus is in equilibrium with the room air, all temperature sensors should indicate the same temperature except for the measurement errors.

4. The heater has been switched on; the power supplied was about $125 \mathrm{~W}$. An optimum heating power should be found so that the relative lost to the surroundings by radiation and convection and hence some fraction of the heat supplied would be lost and the error in the calculation occurred.

5. After approximately thirty minutes time, steady state condition has been achieved.

6. The temperature sensor has been connected to any one of the temperature sensors on the hot side (number 1 and 2 on the Figure 1). The system reaches a steady state condition after sometime. Steady state means the temperature does not change with respect to time. For example, if the temperature does not change by more than $0.1^{\circ} \mathrm{C}$ it may be assumed that the steady state is reached.

7. The readings have been recorded for all the two locations ( 1 on the hot side and 2 on the cold side, see the Figure 1)

8. The experiments have been repeated for different materials. 
9. After experiment was over, the dimmer has been put to zero position and the main switch made off.

\section{Indentations and Equations}

Experiments have been carried out with three different materials namely Brass, Aluminium and Steel for thermal conductivity measurement. Temperatures at inlet and outlet sections have been recorded for three materials. The bar has been heated at its end by heater. The heat would be conducted through the bar to the other end. After attaining the steady state temperature, heat would be transferred from the rod section to the water tank. The enthalpy of water may be calculated by using energy formula i.e.

Enthalpy of water, $Q_{w}=M S\left(T_{f}-T_{i}\right)$

Where,

$M=$ Mass of water. $(K g)$

$S=$ Specific heat of water. $\left(J / \mathrm{kg}^{\circ} \mathrm{C}\right)$

$T_{i}=$ Initial temperature of water. $\left({ }^{\circ} \mathrm{C}\right)$

$T_{f}=$ Final temperature of water. $\left({ }^{\circ} \mathrm{C}\right)$

Again,

Heat losses through water per second may be calculated by using formula,

$\dot{Q}=\frac{Q_{W}}{t}$

Where,

$t=$ Time taken to raise the temperature of water.(s)

$\dot{Q}=$ Heat gained by water per second. $(W)$

Thermal conductivity of bar may be calculatedby Fourier's Laws

$Q=-k A\left(T_{1}-T 2\right) / L$

The negative sign is introduced because heat flows in the direction of decreasing temperature \& serves to make the heat flux in the positive direction.

The measured values of the apparatus are as follows,

$$
\text { Length of test section }(L)=0.05 \mathrm{~m}
$$

Diameter of rod $(d)=0.005 \mathrm{~m}$

Mass of water $(M)$ taken $=0.5 \mathrm{~kg}$

So, the surface area of heat flow $(A)=\pi \times d^{2} / 4$

$$
\begin{aligned}
& =\pi \times 0.005^{2} / 4 \\
& =1.963 \times 10^{-5} \mathrm{~m}^{2}
\end{aligned}
$$

\subsection{Calculation for Brass Material}

Average temperature gradient $=(840+820+820) / 3=826.66 \mathrm{~K} / \mathrm{m}$

During steady state condition water gained $0.65^{\circ} \mathrm{C}$ in fifteen minute time interval

Heat gained by water per second $=(0.5 \times 4200 \times 0.65) / 900$

By conservation of energy principle

$$
=1.51 \mathrm{~W}
$$

Heat loos by rod per second $=$ heat gained by water per second

$-k A\left(T_{1}-T_{2}\right) / L=1.51$

$k \times 1.963 \times 10^{-5} \times 826.66=1.51$

$k=93.05$

Thermal conductivity of brass material $=93.05 \mathrm{~W} / \mathrm{mK}$

Table 3.1 Temperature at inlet and outlet sections for Brass Material

\begin{tabular}{|c|c|c|c|c|}
\hline S. No. & $\begin{array}{c}\text { Temperature at inlet } \\
\text { section }\left(T_{1}\right)\end{array}$ & $\begin{array}{c}\text { Temperature at } \\
\text { outlet Section } 1\left(T_{2}\right)\end{array}$ & $\begin{array}{c}\text { Change in Temperature } \\
\left(T_{1}-T_{2}\right)\end{array}$ & $\begin{array}{c}\text { Temperature Gradient } \\
\left(T_{1}-T_{2}\right) / L\end{array}$ \\
\hline 1. & 109 & 67 & 42 & 840 \\
\hline 2. & 110 & 69 & 41 & 820 \\
\hline 3. & 111 & 70 & 41 & 820 \\
\hline
\end{tabular}

The standard value of thermal conductivity of homogeneous brass material is $121 \mathrm{~W} / \mathrm{mK}$.

The percentage error for value obtained from experiment with actual value has been calculated. $=23.09$

Percentage error $=(121-93.05) \times 100 / 121$ 
The percentage error in thermal conductivity measurement of brass material was obtained as $23.09 \%$ that is due to deviation from ideal conditions in the experiments.

\subsection{Calculation for Aluminium Material}

Average temperature gradient $=(520+500+440) / 3=486.66 \mathrm{~K} / \mathrm{m}$

During steady state condition water gained $0.69^{\circ} \mathrm{C}$ in fifteen minute time interval

Heat gained by water per second $=(0.5 \times 4200 \times 0.69) / 900$

By conservation of energy principle

$$
=1.61 \mathrm{~W}
$$

Heat loos by rod per second = heat gained by water

$-k A\left(T_{1}-T_{2}\right) / L=1.61$

$k \times 1.963 \times 10^{-5} \times 486.66=1.61$

$k=168.53$

Thermal conductivity of aluminium material $=168.53 \mathrm{~W} / \mathrm{mK}$

Table 3.2 Temperature at inlet and outlet sections for Aluminium

\begin{tabular}{|c|c|c|c|c|}
\hline S. No. & $\begin{array}{c}\text { Temperature at inlet } \\
\text { section }\left(T_{1}\right)\end{array}$ & $\begin{array}{c}\text { Temperature at } \\
\text { outlet Section } 1\left(T_{2}\right)\end{array}$ & $\begin{array}{c}\text { Change in Temperature } \\
\left(T_{1}-T_{2}\right)\end{array}$ & $\begin{array}{c}\text { Temperature Gradient } \\
\left(T_{1}-T_{2}\right) / L\end{array}$ \\
\hline 1. & 114 & 88 & 26 & 520 \\
\hline 2. & 115 & 90 & 25 & 500 \\
\hline 3. & 116 & 94 & 22 & 440 \\
\hline
\end{tabular}

The standard value of thermal conductivity of homogeneous aluminium material is $225 \mathrm{~W} / \mathrm{mK}$.

Percentage error $=(225-168.53) \times 100 / 225$

$$
=25.09
$$

The percentage error in thermal conductivity measurement of aluminium material was obtained as $25.09 \%$ that may be accepted due to deviations from ideal conditions in the experiment.

\subsection{Calculation for Steel Material}

Average temperature gradient $=\frac{920+900+860}{3}=893.33 \mathrm{~K} / \mathrm{m}$

During steady state condition water gained $0.52^{\circ} \mathrm{C}$ in fifteen minute time interval

Heat gained by water per second $=\frac{0.5 \times 4200 \times 0.52}{900}$

$$
=1.21 \mathrm{~W}
$$

By conservation of energy principle

Heat loos by rod per second $=$ heat gained by water per second

$-k A\left(T_{1}-T_{2}\right) / L=1.21$

$k \times 1.963 \times 10^{-5} \times 893.33=1.21$

Thermal conductivity of steel material $=69 \mathrm{~W} / \mathrm{mK}$

$$
k=69
$$

The standard value of thermal conductivity of homogeneous steel material is $45 \mathrm{~W} / \mathrm{mK}$.The percentage error has been calculated.

Table 3.3 Temperature at inlet and outlet sections for Steel

\begin{tabular}{|c|c|c|c|c|}
\hline S. No. & $\begin{array}{c}\text { Temperature at inlet } \\
\text { section }\left(T_{1}\right)\end{array}$ & $\begin{array}{c}\text { Temperature at } \\
\text { outlet Section } 1\left(T_{2}\right)\end{array}$ & $\begin{array}{c}\text { Change in Temperature } \\
\left(T_{1}-T_{2}\right)\end{array}$ & $\begin{array}{c}\text { Temperature Gradient } \\
\left(T_{1}-T_{2}\right) / L\end{array}$ \\
\hline 1. & 96 & 50 & 46 & 920 \\
\hline 2. & 97 & 52 & 45 & 900 \\
\hline 3. & 99 & 56 & 43 & 860 \\
\hline
\end{tabular}

Percentage error $=(69-45) \times \frac{100}{45}=53.33$

The percentage error in thermal conductivity measurement of steel material was $53.33 \%$. The larger value of error may be due to the unavailability of exact composition of the alloy. 


\section{Figures}

Some important figures used in Thermal Conductivity Measurement Apparatus are

\subsection{RTD Sensor}

An RTD (resistance temperature detector) is a temperature sensor that operates on the measurement principle that a material's electrical resistance changes with temperature. The relationship between an RTD's resistance and the surrounding temperature is highly predictable, allowing for accurate and consistent temperature measurement. By supplying an RTD with a constant current and measuring the resulting voltage drop across the resistor, the RTD'sresistance can be calculated, and the temperature can be determined.

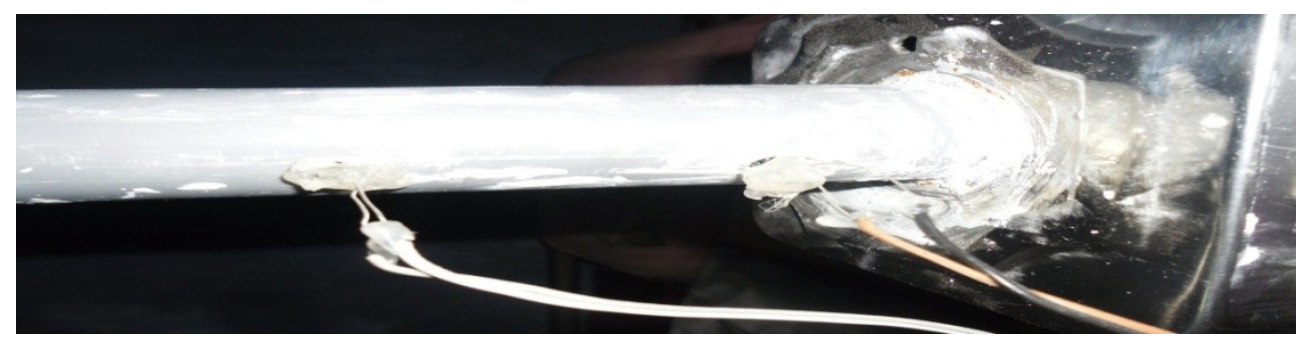

\subsection{Water Tank}

The purpose of water tank was the measurement of heat loss from the metal rod. The water tank is surrounded by the thermocol material (TM) which reduces the heat loss from water to the surrounding atmosphere.

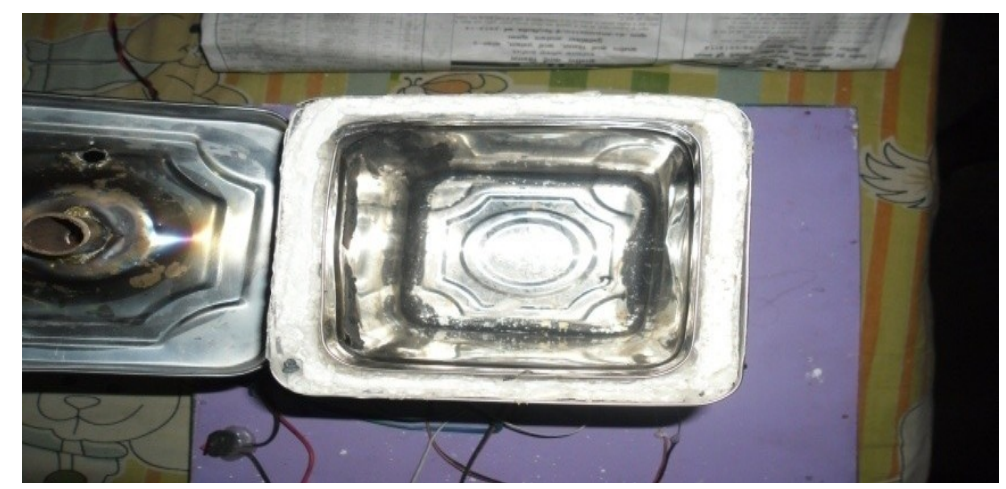

Figure 4.2: Water Tank

\section{3: Temperature Display}

The temperature display is important part of thermal conductivity measurement apparatus. Its work to display the temperature of two different sections on display screen. The temperature of first section display first and temperature of other section display last.

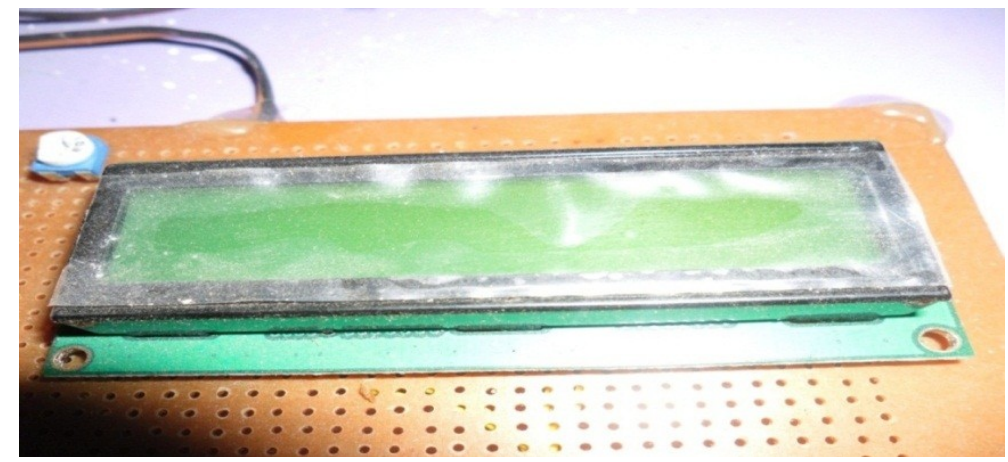

Figure 4.3: Temperature Display 


\section{4: Thermometer}

Mercury Laboratory Thermometer was used to measure the temperature of water heated during experiment until to achieve steady state condition. The mercury Laboratory thermometer had range of $-10^{\circ} \mathrm{C}$ to $110^{\circ} \mathrm{C}$ to measure the temperature of water.

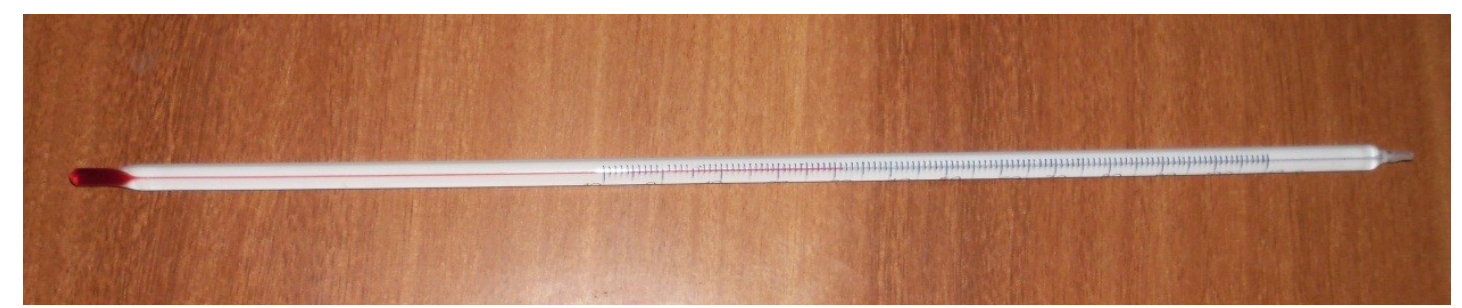

Figure 4.4: Thermometer

\section{Conclusion}

The following conclusions were drawn on the basis of experimental results obtained. An experimental investigation measuring the thermal conductivity of three different engineering materials like brass, aluminium and steel with a thermal test rod in the presence of energized heat sources was conducted. The summaries of results obtained from experiment are following.

I. The thermal conductivity of brass material was obtained $93.05 \mathrm{~W} / \mathrm{mK}$ during experiment. But the standard value thermal conductivity of brass material is $121 \mathrm{~W} / \mathrm{mK}$. The percentage error in the value of thermal conductivity of brass was obtained as $23.09 \%$ during experiment.

II. The thermal conductivity of aluminium material was obtained $168.53 \mathrm{~W} / \mathrm{mK}$ during experiment. But the standard value of thermal conductivity of aluminium material is $225 \mathrm{~W} / \mathrm{mK}$.The percentage error in the value of thermal conductivity for aluminium was obtained as $25.09 \%$ during experiment.

III. The thermal conductivity of steel material was obtained $69 \mathrm{~W} / \mathrm{mK}$ during experiment. But the standard value of thermal conductivity of steel material is $225 \mathrm{~W} / \mathrm{mK}$. The percentage error in the value of thermal conductivity for steel was obtained as $53.33 \%$ during experiment.

\section{References}

[1]. Holman, J.P., 2001, "Experimental Methods for Engineers," 7th ed., McGraw-Hill, New York.

[2]. Jensen, C., Xing, C., Ban, H., Barnes, C., and Phillips, J., 2010, "A Thermal Conductivity Measurement System for Fuel Compacts, "International Mechanical Engineering Congress and Exposition Vancouver, British Columbia.

[3]. Rajput, R.K., 2012, "Heat and Mass Transfer," 5th ed., S.Chand, New Delhi.

[4]. Van Dusen, M., and Shelton, S., 1934, "Apparatus for measuring thermal conductivity of metals up to 600 C," Bureau of Standards Journal of Research, 12, pp. 429-440.

[5]. Francl, J., and Kingery, W., 1954, "Apparatus for Determining Thermal Conductivity by a Comparative Method," Journal of the American Ceramic Society, 37.

[6]. Mirkovich, V., 1965, "Comparative Method and Choice of Standards for Thermal Conductivity Determinations," Journal of the American Ceramic Society, 48(8), pp. 387-391.

[7]. Alam, M., and Rahman, S., and Halder, P.K., 2012, "Lee's and Charlton's Method for Investing of Thermal Conductivity of Insulating Material," ISOR Journal of Mechanical and Civil Engineering, ISSN: 2278-1684Vol-3, PP 53-60,Bangladesh

[8]. Hsieh, Hsiao-an.,1983,"Thermal Conductivity Measurements with a Thermal Probe in the Presence of External Heat Sources," Georgia Institute of Technology.

[9]. Miller, R. A., and Kuczmarski, M. A., 2009, "Method for Measuring Thermal Conductivity of Small Sample Having Very Low Thermal Conductivity," NASA Glenn Research Centre Cleveland, Ohio.

[10]. Hooper, F. C., and Lepper, F. R., 1950, "Transient Heat Flow Apparatus for the Thermal Conductivity Probe," Transaction of the American Society of Heating and Ventilating Engineers, Vol. 56, pp. 309-324.

[11]. Presley, M. A., and Christensen, P. R., 1997,"Thermal Conductivity Measurements of Particulate Materials," Journal of Geophysical Research, Vol. 102, No. E3, pp. 6535-6549.

[12]. Wang, X., Hu1, H., 2001, "Photo-Acoustic Measurement of Thermal Conductivity of Thin Films and Bulk Material," School of Mechanical Engineering, PurdeUniversity,Vol. 123, West Lafayette

[13]. Stojanovic, N., Yun, J., Berg, J. M.,Holtz, M., and Temkin, H., 2011, ”Analysis for Thermal Conductivity Measurement Using Microelectrothermal Test Structures," ASME International Mechanical Engineering Congress and Exposition, pp. 385-391,Vol. 11 ,Colorado, USA.

[14]. Rayeshi, M. R., Amiri, S., 2011” Analysis of One Dimensional Hyperbolic Heat Conduction in a Functionally Graded Thin Plate," ASME 8th Thermal Engineering Joint Conference, pp. T10035, Paper No. AJTEC2011-44237, Hawaii, USA.

[15]. Miyazaki, k., Tanaka, S., Nagai, D., 2012,’Heat Conduction of Porous Material,” Journal of Heat Transfer, Vol. 134, Japan. 